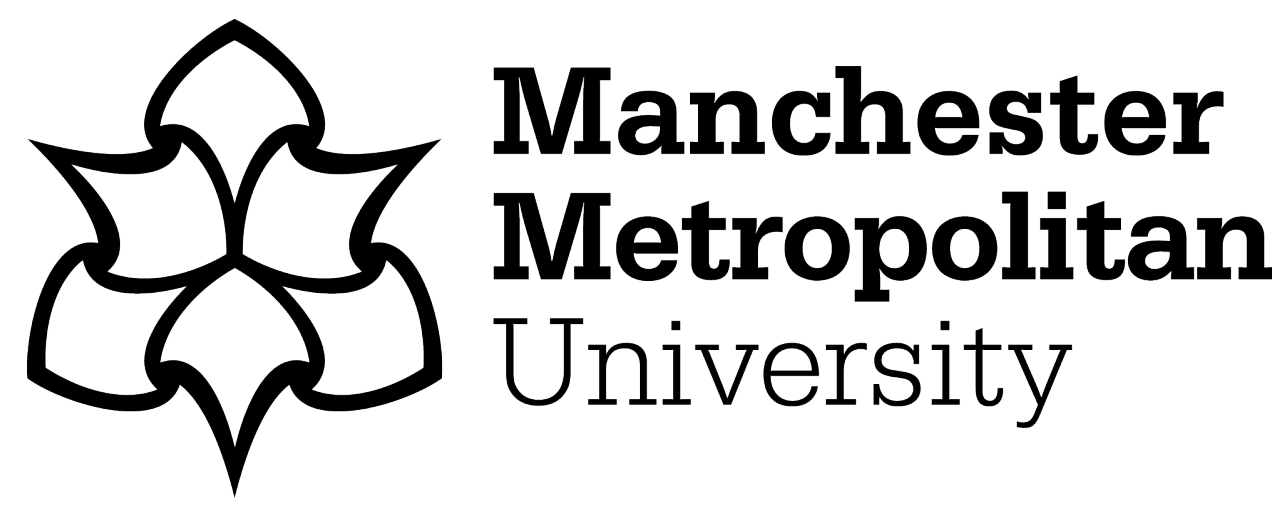

Chantler, Khatidja ORCID logoORCID: https://orcid.org/0000-0001-91292560 and Smailes, Sophie ORCID logoORCID: https://orcid.org/0000-00033867-189X (2004) Working with differences: Issues for research and counselling practice. Counselling and Psychotherapy Research, 4 (2). pp. 34-39. ISSN 1473-3145

Downloaded from: https://e-space.mmu.ac.uk/617501/

Version: Accepted Version

Publisher: Wiley

DOI: https://doi.org/10.1080/14733140412331383933

Please cite the published version 


\title{
Working with differences: issues for research and counselling practice
}

\author{
Khatidja Chantler, Sophie Smailes
}

This paper considers our experience within a group researching domestic violence in minoritised groups and the implications for counselling practice. Issues of race, gender and power were significant within the research team. These issues are intrinsic to minoritised women's experiences of service responses and are also a powerful, yet often unexplored, dynamic in counselling practice. We reflect on issues of 'outsiders' and 'insiders' in terms of the research process and findings, and the impact and influence of these power roles on counselling practice. We acknowledge that it is only by retrospectively engaging with each other and our differences that we have been able to explore our parallel processes and consider their implications for counselling practice.

Key words: research process, minoritisation, parallel process, power, race, counselling

A buse, including domestic violence, features heavily in what clients bring to counselling. Survivors and feminist researchers have long argued about the central role that abuse plays in mental distress (Arnold 1994, 1995; Pembroke 1994). This concern is formally recognised by the Department of Health in its national women's mental health strategy, which acknowledges the links between abuse and mental dis-ease (DoH, 2002). Yet despite increasing discussion around the impacts and influence of abuse, the experiences of minoritised women are overlooked (Aitken and Burman 1999; Burman et al, 1998). This omission is also reflected at a policy level (Chantler, 2002). Our original study, From Violence to Independence, (Batsleer et al, 2002) increased understanding of the multi-dimensional nature of abuse by exploring common experiences of women and highlighting the minoritised dimensions of abuse, which are rarely acknowledged.

We use the term 'minoritised', rather than minority ethnic group, to highlight that groups do not occupy the position of minority by virtue of some inherent property (eg of their culture or religion), but acquire this position as an outcome of a socio-historical process.
This article reflects on one aspect of the original study, that is, the relationships within the research team. We explore the ways in which 'findings' are generated not only by traditional research activity but also by reflecting on our selves as researchers, as well as the experiences generated during the research process. Such a reflexive process draws on counselling and psychotherapy theory and practice, and has implications for counselling as a whole, as well as for minoritised women with experiences of domestic violence (Burman and Chantler, forthcoming). We begin by briefly describing our original study and then introduce ourselves. The paper uses our individual voices to illustrate the different and sometimes competing perspectives about the nature of our enquiry and process. We then draw on three issues of particular relevance to the research and our process:

- the impact of culture, 'race' and gender

- tensions between task and process

- 'outsiders' and 'insiders'.

We relate these topics to the research process and findings, and elaborate on our process within the research. We highlight the implications for counselling and research practice. 


\section{What does this study explore?}

- The experience of relationships based on differences within a research team

\section{Aims and methods}

The study, From Violence to Independence, was an 11-month project jointly funded by the European Social Fund and the Manchester Metropolitan University (September 2001-July 2002). It sought to identify, model (as in the group work intervention, see phase 3) and evaluate support services for African,

African-Caribbean, Irish, Jewish and South Asian women living with or escaping from domestic violence.

The qualitative approach had three phases: - 13 1:1 organisational interviews (plus 26 secondary contacts). Organisations included those working specifically in domestic violence (eg minoritised women's refuges), other support agencies (eg social services, health) and minoritised community-based groups.

- 25 in-depth 1:1 interviews with survivors from the above cultural backgrounds. Participants were accessed through refuges, other service providers, 'snowballing' and networks. All participants were unknown by the interviewers. Issues of consent and confidentiality, and practicalities such as language, childcare, transport and venue were resolved prior to interviews taking place. - Facilitation of three support groups for women with experiences of domestic violence based on the expressed views of interviewees. Participants were primarily selfselected from the interviews. Others were drawn through further 'snowballing' as well as through our networks with services.

Where permission was given, interviews were taped and transcribed. A thematic approach was used, drawing out parallels and contrasts.

The project team comprised seven culturally diverse women based within the Women's Studies Research Centre of the university. Team members came from various professional backgrounds and institutional positions across three departments. They were attached to the project for different periods of time and were variously funded.

\section{Introducing ourselves}

I (Sophie) am a white, middle-class woman and work as a lecturer, researcher and personcentred counsellor. As a counsellor, I work in two voluntary organisations in Manchester. My interest and commitment to the work of this research is informed by personal, political and professional factors. I am committed to working with women in ways that reflect and bring to light their lives and realities. The project appealed because it looked at issues of minoritisation and diversity in relation to healthcare. My involvement is also informed by working therapeutically with women who have experienced domestic violence. This interest and commitment extends to exploring and engaging with reflexive practice in both my therapeutic and academic professions.

I (Khatidja) describe myself as South Asian and an independent researcher, trainer, counsellor and supervisor - and a co-director of this project. My interest in research arises from a practitioner base spanning health and social care work in the UK statutory and voluntary sectors. In the course of my working experience, one of my persistent observations has been the marginalisation of certain groups within service development and provision. This experience parallels John McLeod's (1993) observation: 'On the whole, the theory and practice of counselling and psychotherapy have served the dominant groups in society and largely ignored the problems of people who are discriminated against.'

Even where organisations attempt to redress such inequalities they are frequently overwhelmed by the complexity of initiating and sustaining coherent changes, and by their own anxieties, particularly in relation to race (Chantler et al, 2001). For me, research is also a political intervention influenced by my gender, class and race.

\section{Race, culture and gender}

My (Sophie) experience of working in the research team reflected processes in the outside world. Initially I found I was monitoring my talk, responses and feelings for fear of getting it wrong or being experienced as culturally/racially insensitive. Race/culture anxiety is well founded as we live in a society that allocates meaning, value and power to different sections of society based on perceived racial, cultural, class and gender norms. Consciously or not, we engage with notions of racism, sexism, classism, etc. We may take such 'baggage' with us and recreate research and counselling relationships based on racist/ sexist/classist forms. We all have a stock of experiences with which to inform and measure our understanding. These can highlight 


\section{'Our different roles within the research and the way we were brought in, our academic/ professional backgrounds and our personal/ cultural identities, all played a part in the process of the research team'}

inequities where there were believed to be none and perhaps inform perceptions of discrimination where there is none. Fear of getting it wrong can affect our responses and understanding. We may be informed by narrow assumptions and stereotypes. Our findings highlight how political correctness can silence and disable the debates and discussions that are so necessary to engage constructively with issues of culture, race and gender.

I thought that as a group of women working together there would be a cooperative and collaborative process where issues of power and roles would not be of particular relevance. However, our different roles within the research and the way we were brought in, our academic/professional backgrounds and our personal/cultural identities, all played a part in the process of the research team (Bhavanni and Phoenix, 1994).

My belief that issues of power and role would not be particularly relevant to the research team paralleled the assumptions of some organisations we researched which took a 'blanket approach' in providing services to women. Unless differences were made explicit everyone was positioned as the same.

However, ignoring minoritised women's political, social, cultural and religious realities evades issues of power and invisibility between minoritised and dominant groups (Lewis, 1998).

Failure to acknowledge difference perpetuates notions of universality in terms of world views and meanings (Lyddon, 1998). What is understood as 'normative' to one person is assumed to be the same for another (Ahmad, 1996).

As co-director of the research project and a South Asian woman, I (Khatidja) transgressed some deeply-held beliefs about what my place is or should be. Positioned as powerful (job role) and passive (stereotype attributed to Asian women) presented many challenges that manifested themselves in complex ways. Perhaps because of this, I (more so than my fellow co-director) became the container for difficult and painful emotions, particularly anger. Differences between team members were not openly addressed and this may not have been considered necessary at the beginning of the project in the interests of collaborative working, establishing trust and creating a safe space. No doubt much of this was also informed by the assumptions that as women committed to working on this project we would have few differences and would be able to iron them out relatively easily.
This assumption of consensus proved problematic when I exercised my authority as co-director. I became a persistent advocate for a South Asian women's group which was in danger of disappearing. The practical difficulties of organising and delivering services in more than one language, and fears and anxieties about differences in culture often meant that services respond with indifference and lack of engagement to South Asian women. I felt this response was paralleled in the research team. I wanted not only to highlight the difficulties of organising such a group but also to make available time and space to think and act creatively to overcome some of these obstacles. My commitment was driven from a political base but it was perceived by some members of the research team as being managerial, bureaucratic and output driven.

My main support came from my fellow codirector, a white Jewish woman, rather than the other Black researchers in the group. Notions of 'cultural matching' that feature so markedly in the concept and design of services need to be used with caution (Burman et al, 1998; Chantler et al, 2001).

What can we learn from this for counselling practice? First, exploring client preferences inevitably means addressing differences in culture or identity in counselling relationships and working with the implications. Central to this process is an active involvement with issues of power relations. For person-centred counsellors, the concepts of racialised and gendered conditions of worth may be useful in considering how our own identities impact on our work with clients (Chantler, 2004; Shafi, 1998). This risks bringing to the surface stereotypes within counselling relationships of race, gender and domestic violence. For example, within some of our interview material domestic violence was thought to occur particularly within Orthodox Jewish and Irish Traveller communities. These stereotypes not only pathologise these groups but can also lead to us abandoning hope for the women and ourselves, and/or a normative acceptance of this violence. Awareness and engagement with our own beliefs is crucial to working effectively in this area.

Second, in client-led therapy we may be anxious about raising issues the client has not articulated. Our role is to work within the client's internal frame of reference, which may mean that differences and diversity are not explicitly voiced or considered. However, as a key aspect of therapy is about attending to the unspoken in a sensitive and timely way, we 
argue that 'differences' form an important part of the unspoken and are therefore a legitimate and necessary area of exploration.

Third, what are the costs of silencing difference? Our experience indicates that earlier attention to team differences might have facilitated a speedier resolution to conflicts by creating an environment where it was possible to discuss similarities and differences. We discussed issues around difference with our research participants and steering group but as a research team we seemed less inclined to engage with our own differences. Perhaps our assumptions of a common political commitment lulled us into a false sense of security. Similarly in a counselling relationship, commitment to the client's wellbeing may also result in a silencing of differences. Failure to attend to difference silences a potentially fruitful exploration for counsellor and client and reinforces prevailing power relations.

\section{Task and process: practical versus emotional}

The research left us in no doubt about the large volume of work involved in supporting (minoritised) women with experiences of domestic violence. Often this was without adequate resourcing or proper staff support.

Domestic violence services can be preoccupied with task-focused responses (eg housing, finances, education) which, while vital to a woman's move to independence, can overlook her emotional experiences. The focus on practical interventions helps organisations manage the overwhelming nature of survivors' experiences. This was reflected in some of the survivor accounts where women were expected to manage the enormous emotional upheaval in relation to the practical 'setting up home independently of their abuse/r' with limited resources. They were also expected to put aside complex feelings generated by their abuse.

Here we noticed a striking parallel between the research team and our findings. Like the agencies we were researching, the research team had to focus on tasks to complete the research project within a tight timescale. In doing so, it often felt that there was insufficient time to process the feelings generated by the research, particularly when researchers were interviewing survivors and thinking about setting up the group work. This was despite our endeavours to attend to process and emotional responses by providing space within the research team for discussion, as well as non-managerial supervision. Members of the team accessed support in a variety of ways, as support was acknowledged as both necessary and helpful to the research process. Emotional responses to interview material as well as to other aspects of the research process were valued as a significant contributor to reflexive practice. The frequently painful nature of these emotional responses was often a challenging and uncomfortable experience within the research team. These difficulties further emphasise the complex nature of abuse and the messiness of working with both emotional processes and practical necessities.

Our research clearly demonstrated the need to attend to both the practical and emotional needs of women experiencing domestic violence (Batsleer et al, 2002). Practical issues such as finance, housing, jobs, transport, safety and security, health and childcare have an impact on our clients' wellbeing. We can support clients' emotional responses but also have to work with the unremitting powerlessness and poverty in many women's lives. To ignore this is to ignore the individual's frame of reference and to diminish their reality. Paying attention to racial, social, economic, cultural and political contexts acknowledges that we are part of a racially, sexually, materially and culturally oppressive society. Our clients' and our own subjectivities are informed by these contexts (Lyddon 1998; Guillaumin 1995; Pope-Davis and Liu, 1998). These form part of the counselling relationship and it is of central importance to our practice to pay attention to the implications of our clients' and our own identities, and to the power dynamics inherent in both counselling and research relationships.

Our study illustrated that paying attention to practical interventions such as free childcare, transport and translators facilitated women's choices to access our group work, as did working explicitly with cultural and religious beliefs.

\section{Insiders/outsiders}

As a research team we worked closely and met regularly. As indicated above, in the process of forming the three support groups a number of difficulties were encountered that made the possibility of developing a South Asian women's group unlikely. It was then that another worker was brought into the research team to help. I (Sophie) found this difficult because I felt voiceless and powerless and, as a consequence, inadequate and resentful. Interestingly, I feel that this was reflected in our research, both from an organisational

‘Earlier attention
to team
differences
might have
facilitated
a speedier
resolution to
conflicts by
creating an
environment
where it was
possible to
discuss
similarities
and differences'


view where difficulties in meeting needs are hard to acknowledge and can 'freeze' further action, but also in terms of the distress of not being able to meet needs (Warshaw, 1994). The research team was then at a particularly discordant stage in terms of communication and process. When two further 'outsiders' were brought in at a later stage, feelings of co-ownership and acceptance had moved on and I, for one, no longer felt threatened by this notion of outsiders.

While recognising the discomfort of the research team about introducing an 'outsider', I (Khatidja) had an alternative interpretation of the discomfort. It seemed that much of the research team's anxiety mirrored the situations of women and children experiencing domestic violence. Domestic violence is characterised by secrecy, a sense of failure and the shame of bringing in outsiders. These emotions were present in the research team and and had they persisted, the South Asian group would almost certainly not have been set up. A practical way forward was to bring in the 'outsider'. It was also an important, if difficult, challenge to try and secure the establishment of the South Asian group. Some people thought that my focus was about ensuring that the research remit was delivered and that this dictated the process. This was partly true but I was also influenced by wanting to establish group work for those groups that traditionally find it hardest to access services. This was the impetus behind bringing in the 'outsider'.

Bringing in an 'outsider' was not about our failings but about linking with resources better placed to meet the women's needs. A balance of working through the difficulty and appropriately referring on to another worker is an integral part of our work as counsellors; it is about knowing our limitations and boundaries and being able to communicate them.

In an ideal world clients should have a choice of counsellors. The diversity of available counsellors as well as money, transport, childcare, access, language and immigration status limit this choice. To provide women with the choice of culturally-specific and non-specific groups is hard work and requires a proactive, political commitment to issues of equality.

Being transparent with ourselves and clients about differences facilitates our work with minoritised clients. If we assume the 'outsider' position we must be able to work with the feelings that this generates - both within the counselling relationship and in supervision. What assumptions and stereotypes are we working with? What are our fears and anxieties about working across differences and about issues of domestic violence? How are the power dynamics impacting on the counselling process? The corresponding position of 'insider', that is, a counsellor with a similar cultural background, or with personal experiences of domestic violence, needs just as much scrutiny, for it too has a set of assumptions that influence our practice. As confirmed by our participants, cultural matching is not always the desired model (Burman et al, 1998; Shafi, 1998; Netto et al, 2001).

\section{Concluding comments}

Our culturally diverse research team struggled to explore issues of diversity within the group. Our reflections allowed us to understand each other's perspectives more fully. Significant themes emerged that present challenges to 'working together', including the messiness of attempting to do anti-racist, feminist research.

Our research highlights the need to engage proactively with issues of race, culture and gender, and to develop self-awareness in counselling and research relationships. Failure to do so may mean the underlying dynamics in the relationship remain unexplored. We need to challenge notions of cultural matching as an assumed preference for clients/participants, at the same time respecting the value of culturallyspecific organisations (Batsleer et al, 2002). Our research demonstrated the need for both provisions as indicated by our research participants. This highlights the importance of choice and the need for counsellor preference to rest with clients where possible.

Many domestic violence services put practical concerns above emotional ones. Counselling traditionally privileges emotional concerns. Our findings indicate the need to work with both; to see the link rather than splitting them into two discrete categories. Such a split is unlikely to benefit clients struggling with practical and material realities who need emotional support. Working with a woman whose immigration status allows her no recourse to public funds, who is in an abusive relationship and has little access to practical support, can be so overwhelming that we may overlook or restrict the interconnected nature of the practical and emotional. As counsellors, giving a congruent voice to the overwhelmingness of the encounter, the wanting the story to stop, the distress of staying and being unable to leave, and the feelings of helplessness, can potentially 


\section{What does this study tell us?}

- It is important to recognise differences between members of a research team

- Counsellors need to proactively engage with issues of race, culture and gender, and work with clients' practical as well as emotional concerns

validate our client's experiences.

The shame in recruiting 'outsiders' to our team was a crucial lesson. It highlighted the difficulty in communicating and exploring our own differences. For counsellors this requires a willingness to enter the client's world, no matter how uncomfortable or 'alien'. Frames of references are informed by gender, race, culture, class, sexuality and so on. To take the outsider/insider role is to make assumptions without exploring individual responses.

These themes are relevant to both counselling and research practice, illustrating how the wider political context impacts on what can be told and heard. They highlight the interface between culture, class, gender and abuse and prompt the debate around how we engage with these issues.

Address for correspondence:

Sophie Smailes, S.Smailes@mmu.ac.uk Khatidja Chantler, khatidja.chantler@lineone.net

\section{References}

Ahmed W. (1996) The trouble with culture. In: Kelleher D, Hillier S. (eds) Researching cultural differences in health. London: Routledge

Aitken G. (1996) The present absence/pathologised presence of black women in mental health services. In: Burman E et al. (eds) Psychology discourse practice: from regulation to resistance. London: Taylor \& Francis

Arnold L. (1994) 1. Understanding self-injury 2. Self-help for self-injury 3. Women and self-injury. Bristol: Bristol Crisis Service for Women

Arnold L. (1995) Women and self-injury: a survey of 76 women. Bristol Crisis Service for Women.

Batsleer J et al. (2002) Domestic violence and minoritisation: supporting women to independence. Women's Studies Research Centre. Manchester Metropolitan University.

Bhavnani K-K, Phoenix A. (1994) Shifting identities, shifting racisms. Feminism and Psychology. 4(1)5-18.

Biever J, De Las Fuentes, Cashion L, Franklin C. (1998) The social construction of gender: a comparison of feminist and post-modern approaches. Counselling Psychology Quarterly. 11(2):163-79.

Bondi L, Burman E. (2002) Women and mental health: a feminist review. Feminist Review. 68:6-33.

Burman E, Gowrisunkur J, Sangha K. (1998)

Conceptualising cultural and gendered identities in psychological therapies. European Journal of Psychotherapy, Counselling and Health. 1(2):231-56.

Burman E, Chantler K. (forthcoming) There's no place like home: researching 'race' and refuge provision. Gender, Place and Culture.

Chantler K. (2002) The invisibility of black women in mental health services. Mental Health Review.

Chantler K. (2004) Double edged sword: power and person-centred counselling. In: Moodley R, Lago C, Talahite A. (eds) Carl Rogers counsels a black client. Ross-on-Wye; PCCS Books.

Chantler K, Burman E, Batsleer J, Bashir C. (2001) Attempted suicide and self-harm (South Asian women). Women's Studies Research Centre. Manchester Metropolitan University.

Clarke J, Cochrane A. (1998) The social constructions of social problems. In: Saranga E. (ed) Embodying the social constructions of differerence. London: Routledge.

Culley L. (2000) Working with diversity: beyond the factfile in social work. In: Davies C, Finlay L, Bullman A. (eds) Changing practice in health and social care. London: Sage.

Espin O. (1996) 'Race', racism, and sexuality in the life narratives of immigrant women. In: Wilkinson S. (ed) Feminist Social Psychologies. Buckingham: OUP.

Guillaumin C. (1995) Racism, sexism, power and ideology. London: Routledge.

Lewis G. (1998) Welfare and social constructions of 'race'. In: Saranga E. (ed) Embodying the social constructions of difference. London: Routledge.

Lyddon W. (1998) Social construction in counselling psychology: a commentary and critique. Counselling Psychology Quarterly. 11(2):215-22.

McLeod J. (1993) An introduction to counselling. Buckingham: OUP.

Netto G, Gaag S, Thanki M with Bondi L, Munro M. (2001) A suitable space: improving counselling services for Asian people. Foundation for The Policy Press.

Pembroke L. (1994) Self-harm perspectives from personal experience. London: Survivors Speak Out.

Phoenix A. (1987) Theories of gender and black families. In: Weiner G, Arnot M. (eds) Gender under scrutiny. London: Hutchinson.

Pinkney S. (2000) Anti-oppressive theory and practice in social work. In: Davies C, Finlay L, Bullman A. (eds) Changing practice in health and social care. London: Sage.

Pope-Davis DB, Liu WM. (1998) The social construction of race: implications for counselling psychology. Counselling Psychology Quarterly. 11(2):151-61.

Shafi S. (1998) A study of Muslim Asian women's experiences of counselling and the necessity for a racially similar counsellor. Counselling Psychology Quarterly. 11(3):301-14.

Warshaw C. (1994) Domestic violence: challenges to medical practice. In: Dan A. (ed) Reframing women's health. Thousand Oaks: Sage.

Yuval-Davis N. (1992) Fundamentalism, multiculturalism and women in Britain. In: Donald J, Rattansi A. (eds) 'Race', culture and difference. London: Sage. 